\title{
La recaudación tributaria municipal 2020
}

\author{
Renán Saavedra Sandoval \\ renan.saavedra@hotmail.com \\ Escuela de posgrado \\ Universidad César Vallejo \\ ORCID: 0000-0002-3018-9460 \\ José Manuel Delgado Bardales \\ jmdelgadob@ucvvirtual.edu.pe \\ Escuela de posgrado \\ Universidad César Vallejo \\ ORCID:0000-0001-6574-2759 \\ Scopus autor ID: 24070333700 \\ Código Renacyt: P0050554
}

\section{RESUMEN}

En esta investigación se evalúa las formas de la recaudación tributaria municipal de Estados como España, México, Colombia, Argentina, Ecuador y Perú representados por Lima como Capital del país y la Provincia de Chota. El tipo es cualitativo y el diseño de estudio es una revisión sistemática; las revisiones sistemáticas son investigaciones científicas en las cuales la unidad de análisis son los estudios originales primarios, constituyen una herramienta esencial para sintetizar la información científica disponible, incrementar la validez de las conclusiones de estudios individuales e identificar áreas de incertidumbre donde sea necesario realizar investigación. Sobre recaudación tributaria municipal; en donde a pesar de las enormes diferencias entre las realidades de los estados y ciudades investigadas, las coincidencias en morosidad, falta de información correcta al contribuyente y la necesidad de búsqueda de nuevas estrategias de recaudación, son destacables. Se recomienda aplicar en los municipios, un trabajo coordinado entre las diferentes áreas, de la institución, asimismo inversión en tecnología; capacitación, difusión y la búsqueda de nuevas y mejores estrategias de recaudación tributaria municipal.

Palabras clave: Recaudación, tributaria, municipal. 


\title{
Municipal tax collection 2020
}

\begin{abstract}
In this investigation the forms of the Municipal Tax Collection of States such as Spain, Mexico, Colombia, Argentina, Ecuador and Peru represented by Lima as Capital of the country and the Province of Chota are evaluated. The type is qualitative and the study design is a systematic review, the systematic reviews are scientific investigations in which the unit of analysis is the original primary studies, constitute an essential tool to synthesize the available scientific information, increase the validity of the conclusions of individual studies and identify areas of uncertainty where research is necessary. on municipal tax collection; where in spite of the enormous differences between the realities of the states and cities investigated, the overdue coincidences, lack of correct information to the taxpayer and the need to search for new collection strategies, are remarkable. It is recommended to apply in the municipalities, a coordinated work between the different areas of the institution, also investment in technology; training, dissemination and the search for new and better municipal tax collection strategies.
\end{abstract}

Keywords: Collection, Tax, Municipal.

Artículo recibido: 21 oct. 2020

Aceptado para publicación: 07 nov. 2020 Correspondencia: renan.saavedra@ hotmail.com, Conflictos de Interés: Ninguna que declarar 


\section{INTRODUCCIÓN}

La tributación no siempre ha sido como la conocemos ahora, en tiempos remotos fue la materialización de los resultados de una contienda entre grupos tribales o sociedades medievales; en la que el grupo vencedor imponía a los vencidos, la entrega de sus posesiones (animales, cosechas, y principales bienes) en favor de los vencedores, adicionalmente de sus prisioneros, quienes, por lo general, se convertían en esclavos. En Europa, durante la Edad Media, los tributos los cancelaban los pobladores en especies a los señores feudales, con los vegetales o animales que crecían en las pequeñas parcelas que les eran asignadas, y a la Iglesia Católica en la forma conocida como "diezmos y primicias", de carácter obligatorio y relacionados con la eliminación de posibles cadenas después de la muerte. Los impuestos modernos, como los conocemos hoy, se instauraron a finales del siglo XIX y principios del siglo XX. Dentro de los tributos que se crearon en este período, destacaron: el impuesto sobre la renta al exportador, al importador, al vendedor y los impuestos a la producción, entre otros (la cadena productiva).

En contraste a las prácticas primitivas y medievales europeas, respecto a los orígenes de la tributación, en América, en sus primeras épocas de sociedad organizada, culturas prehispánicas como la Inca, Azteca y Chibcha, recaudaban los tributos de manera justa y proporcional, por medio de un sistema de aportes bien organizados. Esto cambió con la llegada española, a partir del cual se obliga a los indígenas, al pago de diferentes tributos, de acuerdo al monto en metálico y especies, fijado por el corregidor, convirtiéndose en una acción coercitiva y desproporcionada en contra del indígena. Texto extraído de "Cultura Tributaria" de Felicia Bravo.

Por otra parte, desde fines de los años 80, la mayoría de los países de América Latina encaró modificaciones profundas en los sistemas impositivos administrativos por sus gobiernos centrales. Los objetivos perseguidos por estas reformas fueron: a) La búsqueda de mayor neutralidad en la asignación de recursos b) La racionalización del sistema tributario c) la mejora de la equidad del sistema, en su dimensión horizontal y d) el aumento de la recaudación. Sin embargo, hasta la actualidad estas modificaciones no se han implementado en su totalidad (Bes, 1998).

La Constitución Política del Perú 1993, indica que los Gobiernos Regionales y los Gobiernos Locales pueden crear, modificar y suprimir contribuciones y tasas, o exonerar a éstas, dentro de su jurisdicción, y con los límites que señala la ley. La Ley N² 27783, Ley de Bases de Descentralización, manifiesta que la recaudación de los tributos se realiza en los tres niveles de gobierno: Nacional, Regional y Local, cumpliendo cada uno de ellos competencias diferentes en la percepción de los mismos de acuerdo a su jurisdicción. 
Por otra parte, podemos afirmar que en la actualidad, la recaudación tributaria como instrumento de gestión de los diferentes niveles de gobierno del estado peruano, ha tenido siempre un uso muy controversial entre los gobernantes y la población gobernada, ya que en muchos casos su cumplimiento se hace de manera abusiva y desproporcionada; mientras que en otros casos, la gran mayoría de la población evade la contribución tributaria, con ciertas artimañas o simplemente por las ineficiencias, por parte de los entes de gobierno. En el Perú, dos casos latentes que corroboran nuestra afirmación, son: el conflicto entre comerciantes ambulantes y los formales, que se dan en Lima y otras ciudades del país; y la debilidad del estado peruano para cobrar impuestos justos a las grandes transnacionales.

En la actualidad, se necesita de una mayor recaudación tributaria, que garanticen la entrega de mejores servicios a la población, a fin de elevar sus condiciones de vida; pero que dichas contribuciones, deben ser al mismo tiempo, las más justas, equitativas y éticas ¡He ahí el gran desafío! Se formuló como problema: ¿Cuáles son las características de la recaudación tributaria municipal 2020? Y como Objetivo: Conocer las características de la recaudación tributaria municipal 2020.

\section{MATERIALES Y MÉTODOS}

La investigación fue de tipo básica y el diseño fue no experimental de revisión sistemática, las revisiones sistemáticas son investigaciones científicas en las cuales la unidad de análisis son los estudios originales primarios, constituyen una herramienta esencial para sintetizar la información científica disponible, incrementar la validez de las conclusiones de estudios individuales e identificar áreas de incertidumbre donde sea necesario realizar investigación.

La recolección de datos se realizó a través de la revisión bibliográfica de artículos de investigaciones tanto nacionales como internacionales que tuvieron como tema principal, una gestión tributaria municipal de calidad para la mejora de las condiciones de vida de la población; de todos los artículos que se encontraron, se incluyeron los más importantes según nivel de evidencia y se excluyeron los menos relevantes. Se estableció la búsqueda siempre y cuando se tuvo acceso al texto completo del artículo científico.

La técnica de análisis fue la revisión sistemática evaluando cada uno de los artículos para una comparación de los puntos o características en las cuales concuerda y los puntos en los que existe discrepancia entre artículos nacionales e internacionales. Además, de acuerdo a criterios técnicos pre establecidos, se realizó una evaluación crítica e intensiva de cada artículo, a partir de ello, se determinó la calidad de la evidencia y la fuerza de recomendación para cada artículo. 


\section{RESULTADOS Y DISCUSIÓN}

\section{RESULTADOS}

\section{DATOS DE LA PUBLICACIÓN}

\begin{tabular}{|c|c|c|c|c|}
\hline 1. Autor & Año & Nombre de la Investigación & $\begin{array}{l}\text { Revista donde se ubica } \\
\text { la Publicación }\end{array}$ & $\begin{array}{l}\text { Volumen y } \\
\text { Número }\end{array}$ \\
\hline Ruiz, J & 2017 & La cultura tributaria y la gestión municipal. & $\begin{array}{l}\text { https://revistasinvestigac } \\
\text { ión.unmsm.edu.pe/quipu } \\
\text { /article/download } \\
\text { Lima Perú }\end{array}$ & $\begin{array}{l}\text { Vol. } 25 \mathrm{~N}^{\circ} 48 \text { - } \\
2017 \mid \text { Quipukam } \\
\text { ayoc /49 }\end{array}$ \\
\hline
\end{tabular}

\section{CONTENIDO DE LA PUBLICACIÓN}

\begin{tabular}{|c|c|c|c|c|c|}
\hline $\begin{array}{c}\text { Tipo y Diseño } \\
\text { de } \\
\text { Investigación }\end{array}$ & $\begin{array}{l}\text { Población } \\
\text { y Muestra }\end{array}$ & $\begin{array}{c}\text { Instrument } \\
\text { os }\end{array}$ & $\begin{array}{l}\text { Aspectos } \\
\text { ético }\end{array}$ & Resultados & Conclusión \\
\hline Descriptivo & $\begin{array}{l}\text { Revisión } \\
\text { documenta } \\
\text { ria }\end{array}$ & $\begin{array}{c}\text { Ficha de } \\
\text { recolección } \\
\text { de datos de } \\
\text { Publicacion } \\
\text { es }\end{array}$ & $\begin{array}{c}\text { Código de } \\
\text { ética en } \\
\text { investigaci } \\
\text { ón }\end{array}$ & $\begin{array}{l}\text { El promedio de morosidad en el distrito de } \\
\text { Lince representa el } 30,66 \% \text { de la } \\
\text { población contribuyente, casi la tercera } \\
\text { parte, apreciándose un incremento } \\
\text { sustancial en el } 2014 \text {, último año en la que } \\
\text { se hizo el estudio. Esto significa que hay } \\
\text { un incremento de morosidad progresivo en } \\
\text { el distrito de Lince. }\end{array}$ & $\begin{array}{l}\text { La morosidad tributaria debe ser entendida } \\
\text { como ausencia de práctica habitual de } \\
\text { cumplimiento voluntario y consiente de las } \\
\text { obligaciones tributarias y su importancia. Un } \\
\text { gran sector de los vecinos contribuyentes del } \\
\text { distrito de Lince tiene un bajo nivel de } \\
\text { conciencia tributaria. }\end{array}$ \\
\hline
\end{tabular}




\begin{tabular}{|c|c|c|c|c|}
\hline 2. Autor & Año & $\begin{array}{l}\text { Nombre de la } \\
\text { Investigación }\end{array}$ & Revista donde se ubica la Publicación & $\begin{array}{c}\text { Volumen Y } \\
\text { Numero } \\
\end{array}$ \\
\hline $\begin{array}{c}\text { Rodríguez; K y Murillo, } \\
\text { G. }\end{array}$ & 2017 & $\begin{array}{l}\text { La cultura tributaria y } \\
\text { su incidencia en la } \\
\text { recaudación de los } \\
\text { tributos en el Cantón } \\
\text { Babahoyo, Provincia } \\
\text { de los Ríos-Ecuador. }\end{array}$ & $\begin{array}{l}\text { http://dx.doi.org/10.23857/dom.cien.pocaip.2017.3.3.ju } \\
\text { n.45-68 N } \\
\text { URL:http://dominiodelasciencias.com/ojs/index.php/es/ } \\
\text { index Número }\end{array}$ & $\begin{array}{c}\text { Dom. Cien., } \\
\text { ISSN: 2477- } \\
\quad 8818 \\
\text { Vol. 3, núm. 3, } \\
\text { unio, 2017, pp. } \\
\quad 3-23\end{array}$ \\
\hline
\end{tabular}

\section{CONTENIDO DE LA PUBLICACIÓN}

\begin{tabular}{|c|c|c|c|c|c|}
\hline $\begin{array}{c}\text { Tipo y Diseño } \\
\text { de } \\
\text { Investigación }\end{array}$ & $\begin{array}{l}\text { Población y } \\
\text { Muestra }\end{array}$ & Instrumentos & Aspectos ético & Resultados & Conclusión \\
\hline Descriptivo & $\begin{array}{c}\text { Revisión } \\
\text { documentari } \\
\text { a }\end{array}$ & $\begin{array}{l}\text { Ficha de } \\
\text { recolección de } \\
\text { datos de } \\
\text { Publicaciones }\end{array}$ & $\begin{array}{c}\text { Código de ética } \\
\text { en } \\
\text { investigación }\end{array}$ & $\begin{array}{l}\text { Nos manifiesta la poca cultura tributaria que } \\
\text { tiene la población en el Cantón Babahoyo. } \\
\text { El } 80 \% \text { de los encuestados manifiesta que el } \\
\text { documento habilitante es el RUC, } \\
\text { Por lo tanto, el primer paso en cualquier } \\
\text { iniciativa de reformulación de esquema } \\
\text { tributario es elaborar un diagnóstico acerca } \\
\text { de cómo los ciudadanos se apropian de la } \\
\text { información, sobre su contribución. }\end{array}$ & $\begin{array}{l}\text { La formación de la cultura } \\
\text { tributaria está } \\
\text { estrechamente referida a } \\
\text { la calidad de la } \\
\text { información disponible } \\
\text { sobre lo político y a su } \\
\text { implicación en la visión } \\
\text { de la ciudadanía. sobre el } \\
\text { Estado y sus instituciones. }\end{array}$ \\
\hline
\end{tabular}




\begin{tabular}{|c|c|c|c|c|}
\hline 3. Autor & Año & Nombre de la Investigación & Revista donde se ubica la Publicación & $\begin{array}{c}\text { Volumen Y } \\
\text { Numero } \\
\end{array}$ \\
\hline Santilli, D & 2010 & $\begin{array}{l}\text { El papel de la tributación en la } \\
\text { formación del Estado. La } \\
\text { contribución directa en el siglo } \\
\text { XIX en Buenos Aires }\end{array}$ & $\begin{array}{l}\text { http://www.scielo.org.mx/scielo.php?script=sci_ar } \\
\text { ttext\&pid=S1405-22532010000100002 }\end{array}$ & $\begin{array}{l}\text { Am. Lat. Hist. } \\
\text { Econ no. } 33 \mathrm{M} \\
\text { éxico ene./jun. } \\
2010\end{array}$ \\
\hline
\end{tabular}

\section{CONTENIDO DE LA PUBLICACIÓN}

\begin{tabular}{|c|c|c|c|c|c|}
\hline $\begin{array}{c}\text { Tipo y Diseño } \\
\text { de } \\
\text { Investigación }\end{array}$ & $\begin{array}{c}\text { Población y } \\
\text { Muestra }\end{array}$ & Instrumentos & $\begin{array}{l}\text { Aspectos } \\
\text { ético }\end{array}$ & Resultados & Conclusión \\
\hline Descriptivo. & $\begin{array}{c}\text { Revisión } \\
\text { documentari } \\
\text { a }\end{array}$ & 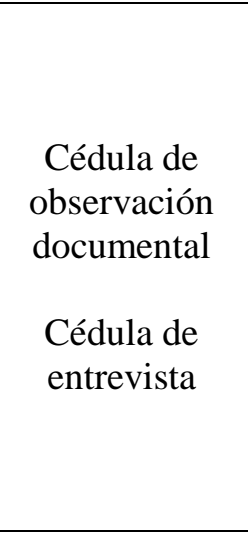 & $\begin{array}{c}\text { Código de } \\
\text { ética en } \\
\text { investigaciór }\end{array}$ & $\begin{array}{l}\text { Una buena parte de la historiografía } \\
\text { ha interpretado a la CD como } \\
\text { reemplazante del diezmo. Los } \\
\text { individuos informados sobre lo } \\
\text { político tienden a mostrar mayor } \\
\text { información sobre lo tributario. Por } \\
\text { otro lado, los ámbitos institucionales } \\
\text { particulares no son transparentes, } \\
\text { con la excepción del vínculo } \\
\text { municipio-impuesto territorial. }\end{array}$ & $\begin{array}{l}\text { En resumen, la historia de la CD } \\
\text { puede ser vista desde dos ángulos. } \\
\text { En primer lugar, podemos } \\
\text { vislumbrar el fortalecimiento } \\
\text { paulatino del Estado centralizado, } \\
\text { capaz de monopolizar la percepción } \\
\text { de impuestos. } \\
\text { Ante cada intento del Estado por } \\
\text { gravar rentas en forma directa se } \\
\text { escuchará la resistencia más o } \\
\text { menos activa de los que se } \\
\text { consideran perjudicados. }\end{array}$ \\
\hline
\end{tabular}




\section{DATOS DE LA PUBLICACIÓN}

\begin{tabular}{|c|c|c|c|c|c|}
\hline 4. Autor & Año & \multicolumn{2}{|c|}{ Nombre de la Investigación } & \multirow{2}{*}{$\begin{array}{l}\text { Revista donde se ubica la Publicación } \\
\text { http://www.scielo.org.mx/scielo.php?script } \\
\text { =sci_arttext\&pid=S1870- } \\
66222017000100035\end{array}$} & \multirow{2}{*}{$\begin{array}{l}\text { Volumen Y Numero } \\
\text { EconoQuantum vol.14 } \\
\text { no.1 Zapopan ene./jun. } \\
2017\end{array}$} \\
\hline $\begin{array}{l}\text { Guillermo, S } \\
\text { Israel, V }\end{array}$ & 2017 & $\begin{array}{l}\text { Recaudación poten } \\
\text { recaudatoria y transfere } \\
\text { análisis para las entida } \\
\text { México utilizando el } 1 \\
\text { estocástica }\end{array}$ & $\begin{array}{l}\text { cial, eficiencia } \\
\text { ncias federales: Un } \\
\text { des federativas en } \\
\text { nodelo de frontera }\end{array}$ & & \\
\hline \multicolumn{6}{|c|}{ CONTENIDO DE LA PUBLICACIÓN } \\
\hline $\begin{array}{c}\text { Tipo y } \\
\text { Diseño de } \\
\text { Investigación }\end{array}$ & $\begin{array}{l}\text { Población y } \\
\text { Muestra }\end{array}$ & $\begin{array}{cc}\begin{array}{c}\text { Instrume } \\
\text { ntos }\end{array} & \begin{array}{c}\text { Aspectos } \\
\text { ético }\end{array}\end{array}$ & \multicolumn{2}{|c|}{ Resultados } & Isión \\
\hline Descriptivo & $\begin{array}{l}\text { Revisión } \\
\text { documentaria }\end{array}$ & $\begin{array}{cc}\text { Ficha de } & \text { Código } \\
\text { recolecció } & \text { de ética } \\
\mathrm{n} \text { de datos } & \text { en } \\
\text { de } & \text { investiga } \\
\text { Publicacio } & \text { ción } \\
\text { nes } & \end{array}$ & \multicolumn{3}{|c|}{$\begin{array}{lll}\text { Mediante el método de Máxima } & \text { El análisis de la estructura de los ingresos de las } \\
\text { Verosimilitud se obtuvieron las } & \text { entidades federativas nos permitió proporcionar } \\
\text { estimaciones de los parámetros del } & \text { evidencia respecto a la fuerte dependencia de las } \\
\text { modelo. Por otra parte, en promedio se } & \text { transferencias federales. Los resultados de la } \\
\text { espera que la recaudación propia de las } & \text { estimación del modelo de frontera estocástica para la } \\
\text { entidades se incremente en } 8.1 \text { por ciento } & \text { recaudación permitieron presentar evidencia de la } \\
\text { por cada millón de habitantes más en una } & \text { presencia de efectos de ineficiencia en el proceso de } \\
\text { entidad. } & \text { recaudo de los ingresos propios de las entidades } \\
& \text { federativas. }\end{array}$} \\
\hline 5. Autor & Año & \multicolumn{2}{|c|}{ Nombre de la Investigación } & Revista donde se ubica la Publicación & Volumen Y Numero \\
\hline Uribe, $M$ & 2016 & $\begin{array}{l}\text { Ley } 1607 \text { de } 2012 \text {, Ot } \\
\text { que No Generó el Impa }\end{array}$ & $\begin{array}{l}\text { a Reforma Tributaria } \\
\text { to Esperado }\end{array}$ & $\begin{array}{l}\text { https://www.uao.edu.co/sites/default/files/Rev } \\
\text { ista\%2013- } \\
\text { 1\%20Julio\%2013\%20Arti\%CC\%81culo\%20 } \\
\text { 1.pdf }\end{array}$ & $\begin{array}{l}\text { Revista de Economía \& } \\
\text { Administración, Vol. } \\
13 \text { No. } 1 . \text { Enero - Junio } \\
\text { de } 2016\end{array}$ \\
\hline
\end{tabular}




\section{CONTENIDO DE LA PUBLICACIÓN}

\begin{tabular}{|c|c|c|c|c|c|}
\hline $\begin{array}{c}\text { Tipo y } \\
\text { Diseño de } \\
\text { Investigación }\end{array}$ & $\begin{array}{c}\text { Población y } \\
\text { Muestra }\end{array}$ & $\begin{array}{c}\text { Instrume } \\
\text { ntos }\end{array}$ & $\begin{array}{l}\text { Aspectos } \\
\text { ético }\end{array}$ & Resultados & Conclusión \\
\hline $\begin{array}{l}\text { Cualitativo y } \\
\text { Cuantitativo }\end{array}$ & $\begin{array}{c}\text { Revisión } \\
\text { documentaria }\end{array}$ & $\begin{array}{l}\text { Ficha de } \\
\text { recolecció } \\
\text { n de datos } \\
\text { de } \\
\text { Publicacio } \\
\text { nes }\end{array}$ & $\begin{array}{l}\text { Código } \\
\text { de ética } \\
\text { en } \\
\text { investiga } \\
\text { ción }\end{array}$ & $\begin{array}{l}\text { Se revela que el impacto final en cuanto al objetivo } \\
\text { empresarial de disponibilidad real de las utilidades, } \\
\text { no es positivo, porque una disminución en el costo } \\
\text { de la mano de obra no significa para la empresa un } \\
\text { beneficio económico mayor. El impuesto a la } \\
\text { equidad puede resultar no ser tan equitativo, pues se } \\
\text { diseñó desde el punto de vista del costo, mas no del } \\
\text { ingreso. }\end{array}$ & $\begin{array}{l}\text { La disminución de un } 13,5 \% \text { en el factor } \\
\text { prestacional establecida en la Ley } 1607 \text { de } \\
2012 \text {, no tiene el efecto de reducción en los } \\
\text { costos laborales que se esperaba. Hay muy } \\
\text { poca migración de empleo informal a } \\
\text { empleo formal, ya que no se ha cambiado } \\
\text { significativamente el contrato de los } \\
\text { empleados }\end{array}$ \\
\hline
\end{tabular}

\section{DATOS DE LA PUBLICACIÓN}

\section{Autor}

Año
El impacto de los precios e

Emmanuel, G

Guillermo, R.

Chaloupka, F impuestos sobre el consumo de productos de tabaco en América Latina y el Caribe https://www.scielosp.org/articl Revisión • Rev Panam Salud Publica 40 (4) e/rpsp/2016.v40n4/272-284/
Oct 2016 •

\section{CONTENIDO DE LA PUBLICACIÓN}

\begin{tabular}{|c|c|c|c|c|c|}
\hline $\begin{array}{r}\text { Tipo y Diseño } \\
\text { de } \\
\text { Investigación }\end{array}$ & $\begin{array}{l}\text { Población } \\
\text { y Muestra }\end{array}$ & $\begin{array}{c}\text { Instrument } \\
\text { os }\end{array}$ & Aspectos ético & Resultados & Conclusión \\
\hline Descriptivo & $\begin{array}{l}\text { Revisión } \\
\text { documentar } \\
\text { ia }\end{array}$ & $\begin{array}{l}\text { Ficha de } \\
\text { recolección } \\
\text { de datos }\end{array}$ & Código de ética en investigación. & $\begin{array}{l}\text { En general, los estudios que examinamos } \\
\text { indicaron que los precios de los cigarrillos } \\
\text { tienen un efecto negativo y } \\
\text { estadísticamente significativo sobre el }\end{array}$ & $\begin{array}{l}\text { Nuestros resultados } \\
\text { confirman la eficacia de los } \\
\text { precios mayores de los } \\
\text { cigarrillos para reducir el }\end{array}$ \\
\hline
\end{tabular}

Ciencia Latina Revista Científica Multidisciplinar, Ciudad de México, México.

ISSN 2707-2207 / ISSN 2707-2215 (en línea), julio-diciembre, 2020, Volumen 4, Número 2. https://doi.org/10.37811/cl_rcm.v4i2.109 p. 728 
consumo de cigarrillos. Las magnitudes del consumo. se puede prever efecto, sin embargo, varían que cualquier aumento de considerablemente entre los estudios y, a impuestos políticamente veces, dentro de estos. Los datos de los factible genere una análisis de series temporales agregadas recaudación tributaria indican que hay una asociación negativa. mayor,

\begin{tabular}{|c|c|c|c|c|}
\hline 7. Autor & Año & $\begin{array}{l}\text { Nombre de la } \\
\text { Investigación }\end{array}$ & Revista donde se ubica la Publicación & $\begin{array}{c}\text { Volumen Y } \\
\text { Numero }\end{array}$ \\
\hline
\end{tabular}

\section{CONTENIDO DE LA PUBLICACIÓN}

\begin{tabular}{|c|c|c|c|c|c|}
\hline $\begin{array}{c}\text { Tipo y Diseño } \\
\text { de } \\
\text { Investigación }\end{array}$ & $\begin{array}{l}\text { Población y } \\
\text { Muestra }\end{array}$ & Instrumentos & $\begin{array}{l}\text { Aspectos } \\
\text { ético }\end{array}$ & Resultados & Conclusión \\
\hline Descriptivo & $\begin{array}{l}\text { Revisión } \\
\text { documentaria }\end{array}$ & $\begin{array}{ll}\text { Ficha } & \text { de } \\
\text { recolección } & \text { de } \\
\text { datos } & \end{array}$ & $\begin{array}{l}\text { Código de } \\
\text { ética en } \\
\text { investigación. }\end{array}$ & $\begin{array}{l}\text { Las contribuciones al isr de personas morales } \\
\text { del régimen general. En este apartado se } \\
\text { desarrolla un análisis de las contribuciones } \\
\text { efectivamente pagadas por isr de las } \\
\text { principales empresas en México. La base } \\
\text { metodológica utilizada como referencia está } \\
\text { constituida por el procedimiento establecido } \\
\text { en la lisr para determinar el resultado fiscal. }\end{array}$ & $\begin{array}{l}\text { Diversos sectores de la sociedad } \\
\text { mexicana coinciden en que la } \\
\text { recaudación tributaria en nuestro } \\
\text { país es inferior al potencial } \\
\text { recaudatorio, y en torno a este } \\
\text { hecho se han generado diversos } \\
\text { espacios de discusión en los que se } \\
\text { argumenta sobre la necesidad de } \\
\text { ampliar la base de contribuyentes, } \\
\text { y elevar la eficiencia recaudadora. }\end{array}$ \\
\hline
\end{tabular}




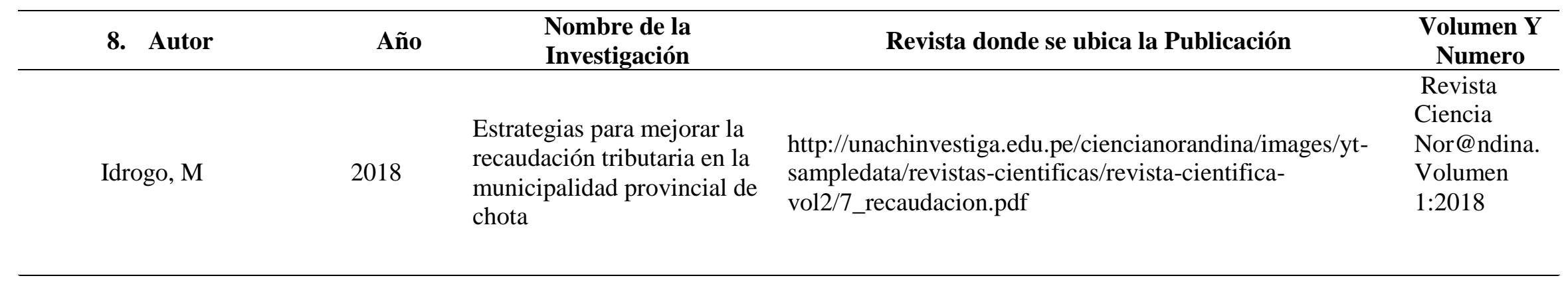

\section{CONTENIDO DE LA PUBLICACIÓN}

\begin{tabular}{|c|c|c|c|c|c|}
\hline $\begin{array}{c}\text { Tipo y } \\
\text { Diseño de } \\
\text { Investigación }\end{array}$ & $\begin{array}{c}\text { Población y } \\
\text { Muestra }\end{array}$ & Instrumentos & $\begin{array}{l}\text { Aspectos } \\
\text { ético }\end{array}$ & Resultados & Conclusión \\
\hline Descriptivo & $\begin{array}{l}\text { Revisión } \\
\text { documentaria }\end{array}$ & $\begin{array}{l}\text { Ficha de } \\
\text { recolección de } \\
\text { datos }\end{array}$ & $\begin{array}{l}\text { Código de } \\
\text { ética en } \\
\text { investigación. }\end{array}$ & $\begin{array}{l}\text { Los resultados del análisis se sustentan } \\
\text { de la relación directa que existen entre } \\
\text { la recaudación tributaria, la } \\
\text { formulación y propuesta de estrategias } \\
\text { hacia la Municipalidad Provincial de } \\
\text { Chota para incrementar la recaudación. } \\
\text { En la municipalidad de Chota no existe } \\
\text { un software sofisticado para el registro } \\
\text { y control de los contribuyentes que } \\
\text { permita su actualización inmediata. }\end{array}$ & $\begin{array}{l}\text { La Municipalidad Provincial de } \\
\text { Chota en los últimos años no cumple } \\
\text { las metas propuestas. } \\
\text { La Municipalidad Provincial de } \\
\text { Chota, no tiene políticas basadas en } \\
\text { orientación al contribuyente que } \\
\text { permita introducir también una } \\
\text { cultura tributaria. } \\
\text { La mayoría de trabajadores adscritos } \\
\text { a la unidad de recaudación no reciben } \\
\text { capacitaciones para el fortalecimiento } \\
\text { de sus capacidades. }\end{array}$ \\
\hline
\end{tabular}




\begin{tabular}{|c|c|c|c|c|}
\hline 9. Autor & Año & $\begin{array}{l}\text { Nombre de la } \\
\text { Investigación }\end{array}$ & Revista donde se ubica la Publicación & $\begin{array}{c}\text { Volumen Y } \\
\text { Numero }\end{array}$ \\
\hline
\end{tabular}

\section{CONTENIDO DE LA PUBLICACIÓN}

\begin{tabular}{|c|c|c|c|c|c|}
\hline $\begin{array}{c}\text { Tipo y } \\
\text { Diseño de } \\
\text { Investigación }\end{array}$ & $\begin{array}{l}\text { Población y } \\
\text { Muestra }\end{array}$ & Instrumentos & $\begin{array}{l}\text { Aspectos } \\
\text { ético }\end{array}$ & Resultados & Conclusión \\
\hline Descriptivo & $\begin{array}{l}\text { Revisión } \\
\text { documentaria }\end{array}$ & $\begin{array}{l}\text { Ficha de } \\
\text { recolección de } \\
\text { datos }\end{array}$ & $\begin{array}{l}\text { Código de } \\
\text { ética en } \\
\text { investigación. }\end{array}$ & $\begin{array}{l}\text { La Constitución Española de 1978, rompiendo } \\
\text { con el centralismo financiero y tributario de la } \\
\text { etapa franquista (Carrillo, 1991), } \\
\text { En España la gestión tributaria y recaudación } \\
\text { de los impuestos locales, tasas, precios } \\
\text { públicos y exacciones locales, puede } \\
\text { realizarse por el propio Ayuntamiento, por } \\
\text { delegación a la Diputación o, incluso se } \\
\text { permite externalizar directamente el servicio, }\end{array}$ & $\begin{array}{l}\text { La gestión tributaria local en } \\
\text { España es una actividad } \\
\text { altamente compleja dado el } \\
\text { cambiante y variado marco legal } \\
\text { que lo sustenta. Es por ello que la } \\
\text { recaudación se puede delegar a } \\
\text { organizaciones } \\
\text { supramunicipales: a la propia } \\
\text { diputación, a Organismo } \\
\text { autónomo especializado e incluso }\end{array}$ \\
\hline & & & & & $\begin{array}{l}\text { a empresas } \quad \text { externas } \\
\text { colaboradoras. }\end{array}$ \\
\hline
\end{tabular}




\section{DISCUSIÓN}

Culminada la revisión sistemática de los artículos, del 100\%, el 22\% corresponden a España, el 22\% a México; mientras que el $11 \%$ a Ecuador, Colombia y Argentina respectivamente; el 22\% corresponden a investigaciones hechas en Perú, tanto en Lima como en el interior del país. En relación a los diseños y tipos de estudios analizados, el 100\% son descriptivos.

Ruiz, J., Concluye que la morosidad tributaria debe ser entendida como ausencia de práctica habitual de cumplimiento voluntario y consiente de las obligaciones tributarias y su importancia, para alcanzar el desarrollo local; siendo la misma, una tarea pendiente de los municipios. Rodríguez; K y Murillo, G. Concluyen que la formación de la cultura tributaria está estrechamente referida a la calidad de la información disponible sobre lo político y a su implicancia en la visión de la ciudadanía sobre el Estado y sus instituciones. Santilli, D; Concluye que la contribución directa tiene 2 efectos: el fortalecimiento paulatino del Estado centralizado, capaz de monopolizar la percepción de impuestos y la resistencia más o menos activa de los que se consideran perjudicados.

Guillermo, S e Israel, V; Concluyen que los resultados de la estimación del modelo de frontera estocástica para la recaudación permitieron presentar evidencia de la presencia de efectos de ineficiencia en el proceso de recaudo de los ingresos propios de las entidades federativas. Siendo el Distrito Federal y Aguascalientes las entidades que mayor y menor esfuerzo recaudatorio realizan respectivamente. Uribe, M; determinó que la disminución de un 13,5 \% de contribución tributaria, en el factor prestacional establecida en la Ley 1607 de 2012, no tiene el efecto de reducción en los costos laborales que se esperaba. Hay muy poca migración de empleo informal a empleo formal, ya que no se ha cambiado significativamente el contrato de los empleados. Emmanuel, G, Guillermo, R. Chaloupka, F; establece que sus resultados confirman la eficacia de los precios mayores de los cigarrillos para reducir el consumo. Se puede prever que cualquier aumento de impuestos políticamente factible genere una recaudación tributaria mayor.

Irene, M; determinó que la gestión tributaria local en España, es una actividad altamente compleja dado el cambiante y variado marco legal que lo sustenta. Estos mecanismos se concretan en la delegación de sus competencias tributarias en organizaciones supramunicipales: en la propia Diputación), en Organismo autónomo especializado o en empresa externa colaboradora. Existe alta morosidad. Rodríguez A. y Ruiz C; establece que la recaudación tributaria en México es inferior al potencial recaudatorio y que existe la necesidad de ampliar la base de contribuyentes. Elevar la eficiencia recaudatoria, con base en los principios de proporcionalidad y equidad en el tratamiento de los sujetos pasivos, constituye una tarea fundamental y un elemento central en la discusión de la reforma fiscal en la agenda nacional. 
Idrogo, M; identificó que la Municipalidad Provincial de Chota en los últimos años no cumple las metas propuestas de recaudación tributaria, por lo tanto, es necesaria la implementación de nuevas estrategias que contribuyan a la mejora de los niveles de recaudación; asimismo no tiene políticas basadas en orientación al contribuyente que permita introducir también una cultura tributaria; no existe la capacitación ni los equipos tecnológicos para mejorar la recaudación.

\section{CONSIDERACIONES FINALES}

La revisión sistemática de los nueve artículos científicos, sobre incremento de la recaudación tributaria municipal, corresponde a diferentes bases de datos de artículos científicos, todos ellos corresponden al tipo y diseño de estudios descriptivos.

Se encontró que el 55.5\% de los estudios relacionados concluyen que existe bajo nivel de recaudación tributaria y un alto porcentaje de morosidad, debido a que los municipios no entregan al contribuyente una información correcta, clara y oportuna, sobre sus responsabilidades tributarias, sus beneficios y la importancia de su contribución, para el desarrollo de su comunidad local.

Por otro lado, el $44.4 \%$ de los estudios analizados concluye, que es necesario la búsqueda e implementación de nuevas estrategias de recaudación en los municipios, para superar el alto índice de morosidad y lograr los objetivos de gobierno local, el de ofrecer a sus ciudadanos servicios de calidad. Resaltamos así mismo que de los estudios analizados el $33.3 \%$ coincide, que una mejor recaudación tributaria está íntimamente relacionada con un mayor nivel de desarrollo local.

En el presente estudio, se observa que: Santilli, D y Uribe, M, tienen opiniones divergentes, mientras que Santilli afirma que la implementación de nuevos impuestos permitidos por la ley fortalece la institucionalidad del estado; Uribe afirma todo lo contrario, ya que afirma que la implementación de nuevos impuestos siempre provocará mayoritariamente el malestar y rechazo de los que se ven como afectados, debilitando la institucionalidad del estado.

En el presente estudio, se observa que: Ruiz, J., Rodríguez; K y Torres; M; e Idrogo, M, tienen opiniones convergentes, en cuanto afirman que con el diseño y aplicación de nuevas estrategias y la información correcta al contribuyente, se puede mejorar la recaudación tributaria municipal y por consiguiente mejorar las condiciones de vida de la población local. 
Los autores Irene, M y Rodríguez A. y Ruiz C, tienen opiniones divergentes en tanto que Irene M. afirma que se puede entregar la difícil tarea de recaudar la contribución inclusive a una empresa, sólo viéndolo desde el punto de vista económico y no las condiciones y posibilidades del contribuyente, Rodríguez A. y Ruiz C, opinan todo lo contrario que la tarea de la recaudación es exclusiva de los municipios y no se puede entregar dicha tarea a una empresa, porque afirman que dicha recaudación debe cumplir los principios de proporcionalidad y equidad del contribuyente.

Finalmente es bueno destacar que el presente estudio de análisis de investigaciones de diferentes realidades como España, México, Argentina, Colombia, Ecuador y Perú, sobre recaudación tributaria municipal, que, a pesar de las enormes diferencias entre dichas realidades, las coincidencias en morosidad, falta de información correcta al contribuyente y la necesidad de búsqueda de nuevas estrategias de recaudación, son destacables.

Se recomienda aplicar en los municipios, un trabajo coordinado entre las diferentes áreas, de la institución, asimismo inversión en tecnología; capacitación, difusión y la búsqueda de nuevas y mejores estrategias de recaudación tributaria municipal.

\section{LISTA DE REFERENCIAS}

Achahui, L. Nueva ley Orgánica de Municipalidades. Editorial EDIGRABER Lima. 2010. P.123. Recuperado de: https://revistasinvestigación.unmsm.edu.pe/quipu/article/download Lima Perú.

Alfaro, J. (2006), Articulo "La Incidencia De Los Gobiernos Locales En Los Impuestos $\begin{array}{lllllll}\text { Municipales En } & \text { El } & \text { Perú” } & \text { LIMA. } & \text { S/E. } & \text { pp }\end{array}$ Recuperadode:https://revistasinvestigación.unmsm.edu.pe/quipu/article/download Lima Perú. Alvarado, P. (2015). Estrategias para optimizar la recaudación del impuesto predial y tasas administrativas en la municipalidad para promover el desarrollo urbano en el distrito de Baños - provincia de Lauricocha - región Huánuco 2014: Tesis para optar el grado de contador público. Universidad Nacional Hermilio Balizan, Huánuco, Perú. Recuperado de: https://revistasinvestigación.unmsm.edu.pe/quipu/article/download Lima Perú.

Avellaneda, B. (2011). Riqueza, pobreza e impuestos como factores de desarrollo, Bogotá (Colombia), Criterio Libre - Vol. 9 • No. 15 • Bogotá (Colombia) • Julio-Diciembre 2011 • Pp. 283-304. BACH. Recuperado de: https://www.uao.edu.co/sites/default/files/Revista\%20131\%20Julio\%2013\%20Arti\%CC\%81culo\%201.pdf 
Baldwin, M. Área Financiera (2014). El cash-pooling y su diseño [en línea]. Madrid. Consulta [2607-2015]. Recuperado de http://www.areafinanciera.com/el-cash-pooling-y-su-diseno/

Belda, J. Evalúe Consultores (2014). Nuevos retos en la gestión financiera: la gestión del circulante [en línea]. Madrid. Consulta [26-06-2015]. UCM - Facultad de CCEE y EE José María Martínez Gonzalo 394 Modelo de gestión financiera basado en la optimización de las NOF 2015. Recuperado de: http://es.slideshare.net/slides_eoi/nuevos-retos-en-la-gestin-financierala-gestindel-circulante-con-jos-manuel-belda.

Canales, J. (2002), Introducción al Gobierno y a la Gestión Local, Alicante, Editorial club Universitario (ECU). Recuperado de: http://dx.doi.org/10.23857/dom.cien.pocaip.2017.3.3.jun.45-68

URL:http://dominiodelasciencias.com/ojs/index.php/es/index Número

Canales, J. (2010), "El nuevo papel del territorio y su incidencia en los gobiernos locales: algunos apuntes sobre el caso español” en Política, Revista del Pensamiento Político, nº 48, pp. 15- 21. Recuperado de: https://www.redalyc.org/pdf/3221/322128446002.pdf

Cuadrado, M. Ministerio de Economía y Hacienda - Instituto de Planificación Contable (1983). Cash-Flow y flujo de recursos. Madrid. Recuperado de: https://www.redalyc.org/pdf/2811/281128985001.pdf

Durán, P. Expansión - Unidad Editorial Información Económica, S.L. (2015). Política de dividendos [en línea]. Madrid. Consulta [21-06-2015]. Recuperado de: http://www.expansion.com/diccionario-economico/politica-de-dividendos.html

Emmanuel, G. Guillermo, R. Chaloupka, F. (2016). El impacto de los precios e impuestos sobre el consumo de productos de tabaco en América Latina y el Caribe. Revisión. Rev. Panam. Salud Publica 40 (4) Oct 2016 https://www.scielosp.org/article/rpsp/2016.v40n4/272-284/

Garde, J. (1999), "Sistema fiscal y modelo social: el alcance de las últimas reformas" en J.A. Garde Roca (ed.), Políticas sociales y Estado de Bienestar en España, Madrid, Editorial Trotta, pp.191-221. Recuperado de: https://www.redalyc.org/pdf/3221/322128446002.pdf

Guillermo, S. Israel, V. (2017). Recaudación potencial, eficiencia recaudatoria y transferencias federales: Un análisis para las entidades federativas en México utilizando el modelo de frontera

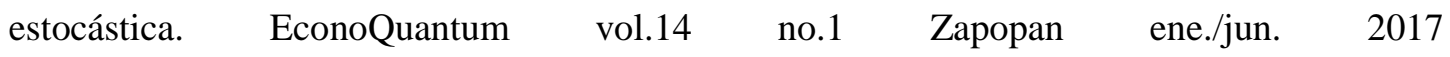
http://www.scielo.org.mx/scielo.php?script=sci_arttext\&pid=S1870-66222017000100035

Idrogo, M. (2018). Estrategias para mejorar la recaudación tributaria en la municipalidad provincial de chota. Revista Ciencia Nor@ndina. Volumen 1:2018 
http://unachinvestiga.edu.pe/ciencianorandina/images/yt-sampledata/revistascientificas/revista-cientifica-vol2/7_recaudacion.pdf

Irene, M. (2013). La gestión tributaria local en España: algunas propuestas solidarias del estado del bienestar ante la crisis global. BARATARIA Revista Castellano-Manchega de Ciencias Sociales $\quad \mathrm{N}^{\mathrm{o}} \quad 15, \quad$ pp. $39-53, \quad 2013, \quad$ ISSN: $1575-0825, \quad$ e-ISSN https://www.redalyc.org/pdf/3221/322128446002.pdf

Lago, J. (1994), “Algunas consideraciones sobre la distribución de competencias de gestión tributaria en España” en El sistema económico de la Constitución española, Madrid, Dirección General del Servicio Jurídico del Estado, Ministerio de Justicia. Secretaria General Técnica, pp. 15621583. Recuperado de: https://www.redalyc.org/pdf/3221/322128446002.pdf

Mira, A. (2000), "La cooperación insular y provincial en materia de gestión tributaria" en Análisis Local, $\quad \mathrm{n}^{\mathrm{o}} \quad 30, \quad$ p. 23-28. Recuperado de: https://www.scielosp.org/article/rpsp/2016.v40n4/272-284/

OCDE (2009), Foro sobre la Administración Tributaria. Subgrupo formado para la información a los contribuyentes, Paris, OECD. Recuperado de: http://www.scielo.org.mx/scielo.php?script=sci_arttext\&pid=S1870-66222017000100035

Rodrigo B. (2011). Perú economía y tributación. Historia de la tributación en el Perú. http://rodrigobordaeso.blogspot.com/

Rodríguez; K. y Murillo, G. (2017). La cultura tributaria y su incidencia en la recaudación de los tributos en el Babahoyo, Provincia de los Ríos-Ecuador. Dom. Cien., ISSN: 2477-8818 Vol. 3, núm. 3, junio, 2017, pp. 3-23. http://dx.doi.org/10.23857/dom.cien.pocaip.2017.3.3.jun.45-68 N URL:http://dominiodelasciencias.com/ojs/index.php/es/index Número

Rodríguez, A y Ruiz C. (2013). Contribución efectiva al Impuesto Sobre la Renta en personas morales del régimen general. Economía: Teoría y práctica, núm. 38, enero-junio, 2013, pp. 949. https://www.redalyc.org/pdf/2811/281128985001.pdf

Ruiz, J. (2017). La cultura tributaria y la gestión municipal. Vol. 25 N 48 - 2017|Quipukamayoc 149. Lima Perú https://revistasinvestigación.unmsm.edu.pe/quipu/article/download

Santilli, D. (2010). El papel de la tributación en la formación del Estado. Am. Lat. Hist. Econ. No.33 México ene./jun. 2010. La contribución directa en el siglo XIX en Buenos Aires http://www.scielo.org.mx/scielo.php?script=sci_arttext\&pid=S1405-22532010000100002

Sosa, F. (2004), La gestión de los servicios públicos locales, Madrid, Civitas RECIBIDO: 20/12/2012 ACEPTADO: 29/1/2013. Recuperado de: http://www.scielo.org.mx/scielo.php?script=sci_arttext\&pid=S1405-22532010000100002. 
Uribe, M. (2016). Ley 1607 de 2012, Otra Reforma Tributaria que No Generó el Impacto Esperado. Revista de Economía \& Administración, Vol. 13 No. 1. Enero - Junio de 2016 https://www.uao.edu.co/sites/default/files/Revista\%20131\%20Julio\%2013\%20Arti\%CC\%81 culo\%201.pdf 